\title{
Study of Oxide-Dispersion-Strengthened Ferritic Steels after Ion Implantation
}

\author{
J. Simeg Veternikova ${ }^{a, *}$, E. Korhonen ${ }^{b}$, M. Skarba $^{c}, J_{\text {. Degmova }}^{a}$, V. Sabelova ${ }^{a}$, \\ S. SOJAK ${ }^{a}$ AND V. SLUGEN ${ }^{a}$ \\ ${ }^{a}$ Institute of Nuclear and Physical Engineering, Faculty of Electrical Engineering and Information Technology \\ Slovak University of Technology, Ilkovicova 3, 81219 Bratislava, Slovakia \\ ${ }^{b}$ Departments of Applied Physics, Aalto University, P.O. Box 11100, FI-00076 Aalto, Finland \\ ${ }^{c}$ Institute of Materials Science, Faculty of Material Science and Technology, Slovak University of Technology \\ Bottova 25, 91724 Trnava, Slovakia
}

\begin{abstract}
This paper is focused on four different commercial oxide-dispersion-strengthened ferritic steels (MA 956, ODM 751, MA 957 and ODS Eurofer) with different chromium content and the change of their microstructure after helium ion implantation. The samples were implanted with kinetic energy of ions up to $500 \mathrm{keV}$ and the implantation depth was up to $1.2 \mu \mathrm{m}$. The implantation was performed at Institute of Nuclear and Physical Engineering, Slovak University of Technology in Bratislava. The samples were observed prior and after the implantation by positron Doppler broadening spectroscopy with slow positron beam (energy up to $36 \mathrm{keV}$ ) which is one of the most suitable techniques due to its sensitivity to surface and subsurface layers up to $1.6 \mu \mathrm{m}$. The results showed visible change of defect presence in all samples and defect depth profiles are in a good accordance with SRIM software calculations displaying the Bragg peak. According to measured data, ODS Eurofer (9\% Cr) seems to be the most radiation resistant from the group of all investigated steels and MA $956(20 \% \mathrm{Cr})$ as the most radiation affected steel.
\end{abstract}

DOI: $10.12693 /$ APhysPolA.125.741

PACS: 61.72.-y, 68.55.Ln, 61.72.J-

\section{Investigated samples}

Four commercial high chromium ferritic ODS steels were investigated: MA 956 and MA 957 (products of Incoloy) [1], ODM 751 (product of Dour Metal) [2] and ODS Eurofer (product of Plansee). Chemical composition of the investigated steels (see Table) was observed by optical emission spectroscopy at the Institute of Materials at Slovak University of Technology.

TABLE

Chemical composition of the investigated ODS steels (in wt\%).

\begin{tabular}{c|c|c|c|c|c|c|c|c|c|c|c|c|c}
\hline \hline Steels & $\mathrm{C}$ & $\mathrm{Mn}$ & $\mathrm{Ni}$ & $\mathrm{Cr}$ & $\mathrm{Mo}$ & $\mathrm{Ti}$ & $\mathrm{Al}$ & $\mathrm{Si}$ & $\mathrm{Nb}$ & $\mathrm{N}$ & $\mathrm{W}$ & $\mathrm{Ta}$ & $\mathrm{Y}_{2} \mathrm{O}_{3}$ \\
\hline MA 956 & 0.1 & 0.12 & 0.07 & 19.9 & 0.1 & 0.3 & 3.4 & 0.04 & 0.01 & 0.04 & - & - & 0.5 \\
ODM 751 & 0.1 & 0.07 & 0.02 & 16.2 & 1.7 & 0.7 & 3.8 & 0.06 & 0.01 & 0.03 & - & - & 0.5 \\
MA 957 & 0.1 & 0.09 & 0.13 & 13.7 & 0.1 & 1.0 & 0.1 & 0.04 & - & - & - & - & 0.3 \\
ODS & 0.1 & 0.44 & - & 8.8 & - & - & - & 0.05 & 0.01 & - & 1.1 & 0.14 & 0.3 \\
Eurofer & & & & & & & & &
\end{tabular}

These investigated ODS steels were produced by mechanical alloying, i.e. matrix materials were milled and mixed together with yttrium particles to form solid solutions with a uniform dispersion of oxide nanoparticles. The mixtures were then consolidated and sintered by hot extrusion (HEx) at $1150^{\circ} \mathrm{C}$ under a pressure of $103 \mathrm{MPa}$. Steel ODS Eurofer was hot isostatic pressed (HIP) at similar pressure and temperature. The recrystallization heat treatment resulted in a coarse columnar grain structure.

*corresponding author; e-mail: jana.veternikova@stuba.sk
The samples of the investigated steels were prepared from as-received material by cutting the steel sheets into suitable pieces. In order to remove surface impurities, the sample surfaces were polished after the milling cutting. This mechanical treatment of samples affects surface and subsurface layers, although samples are polished almost into a mirror level. The zone affected by milling cutting usually goes around $150 \mu \mathrm{m}$ [3], but subsequent grinding removes the most affected subsurface and the powder used for polishing of our samples had particles with size of $0.5 \mu \mathrm{m}$. The roughness of the surface measured by atomic force microscopy [4] achieved up to $35 \mathrm{~nm}$.

\section{Experimental treatment and methods}

The samples were implanted by helium ions at a linear accelerator belonging to the Institute of Nuclear and Physical Engineering, Slovak University of Technology. The main goal of this experiment was to study radiation resistance of individual steels. During ion implantation, point defects usually accumulate into the structure as a result of the atom knocking-on by the helium nuclei [5]. Therefore accumulation of small vacancy defects, which are typical for ferritic structure, was assumed in the investigated ferritic ODS steels.

Helium ions $\left(\mathrm{He}^{2+}\right)$ with a kinetic energy up to $500 \mathrm{keV}$ were implanted into all samples. The planned magnitude of the implantation dose was up to $\approx 1.9 \times 10^{18} \mathrm{ions} \mathrm{cm}^{-2}$. The ion current was kept around value of $5 \mu \mathrm{A}$ during the whole implantation which means that the ion rate was up to $4 \times 10^{13}$ ions $\mathrm{s}^{-1}$. The temperature of samples was maintained up to $100^{\circ} \mathrm{C}$ by cooling system with liquid 
nitrogen; therefore process of diffusion or precipitation was not expected during the implantation.

However, the implantation of the first sample (steel MA 956) demonstrated great eye-visible damage (Fig. 1a), i.e. blistering effect — separation of the top layers from the rest of the sample, even during the two thirds of implantation process. This effect partially distorts positron measurements. Therefore, the implantation parameters (implantation time or dose) had to be inevitably changed. The implantation time stayed unchanged; because we assumed that it is still long in term of eventual undesirable helium escape from the structure. A complete process of implantation for one sample takes more than $7 \mathrm{~h}$. Finally, the implantation dose was reduced into the value where blistering effect only starts to form. The value of new implantation dose was up to $\approx 1 \times 10^{18}$ ions $\mathrm{cm}^{-2}$. Comparison of the samples surface after both implantation doses is shown in Fig. 1.

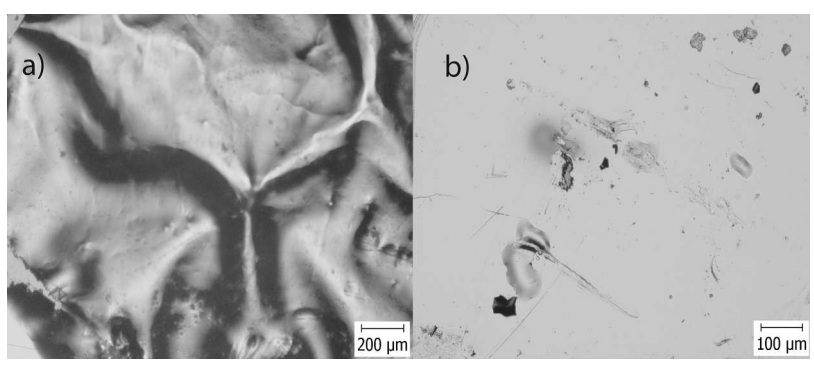

Fig. 1. Optical spectroscopy of implanted MA 956 samples: 1st dose (a), 2nd dose (b).

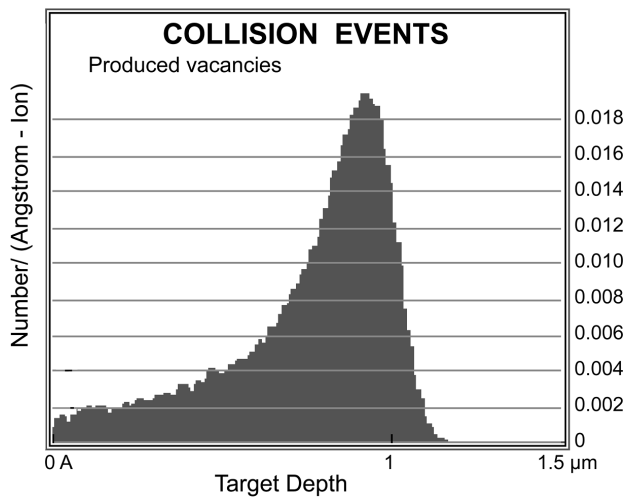

Fig. 2. Simulation of helium ion implantation by SRIM software.

The Bragg peak of the $500 \mathrm{keV}$ implantation is located around $950 \mathrm{~nm}$ according to SRIM simulation [6] shown in Fig. 2. For observation of defect depth profile and created radiation damage, Doppler broadening spectroscopy (DBS) [7] with slow positron beam is one of the most suitable techniques.

The DBS equipment (Aalto University, Finland) with a conventional setup was applied. The DBS spectra were recorded by one HPGe detector with Gaussian resolution function of $1.24 \mathrm{keV}$. The energy window for a calculation of the $W$ parameter is $3 \mathrm{keV}<\left|E_{\gamma}-511 \mathrm{keV}\right|<7.6 \mathrm{keV}$ and for the S parameter $\left|E_{\gamma}-511 \mathrm{keV}\right|<0.83 \mathrm{keV}$. The slow positron beam [8] with ${ }^{22} \mathrm{Na}$ source of positrons and tungsten moderator can achieve energies ranging from 0.5 to $36 \mathrm{keV}$. This technique is able to study defect depth profiles up to $1.6 \mu \mathrm{m}$.

\section{Results and discussion}

The DBS results are given in $S$ parameter whose value usually grows with an increase of a defect presence [9]. The measured data of the investigated ODS steels were supplemented by a reference sample — stainless steel AISI 316L (17Cr12Ni2Mo) formed by classical method without the mechanical alloying, annealed for $4 \mathrm{~h}$ at $800^{\circ} \mathrm{C}$ at the end of the process of fabrication. This steel is considered as structure with minimum defects, almost defect-free structure.

The investigated ODS steels before the implantation demonstrated significant presence of defects in comparison to the reference steel. Their defect concentration slightly decreased in deeper layers. These defects are evidently formed during the process of sample/steel preparation (milling cutting, grinding and polishing). According to results from positron annihilation lifetime spectroscopy (PALS) published in [10], the non-implanted samples contained defects probably with size of three or four Fe-vacancies in predominance. The concentration of these defects was estimated between 0.07 and $1.5 \times 10^{17} / \mathrm{cm}^{3}$ using the calculation from positron trapping rate and PALS results [10].

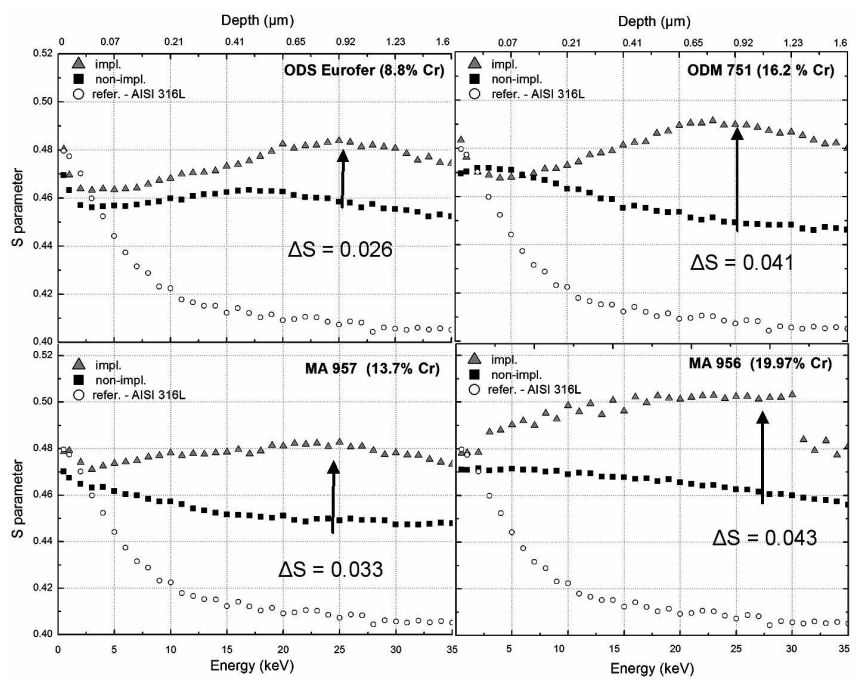

Fig. 3. Comparison of the S parameter for samples before and after the implantation.

After the implantation, the $S$ parameters increased (Fig. 3) which gave proof of the further defect accumulation during the experimental treatment. The lowest increase of the $S$ parameter was observed in steel ODS 
Eurofer, followed by MA 957 and ODM 751. MA 956 has the highest values of the $S$ parameter after the implantation. Material MA 956 has a step change at an energy around $32 \mathrm{keV}(\approx 1.3 \mu \mathrm{m})$ where the implantation of helium ions finished. This material showed formation of the blistering effect, even after the application of the reduced implantation dose, which can explain the step change of the $S$ parameter.

The Bragg peak of the implantation was found as the maximum value of the depth defect profile; although the real depth was smaller than the value predicted by SRIM software $(\approx 950 \mathrm{~nm})$ and moves between 770 and $880 \mathrm{~nm}$. The total radiation damaged zone was larger than the predicted zone, which was probably caused due to helium diffusion and accumulation in layers deeper than $1.2 \mu \mathrm{m}$. The DBS results determined steel ODS Eurofer as the material with the best resistance to the accumulation of vacancy defects.

\section{Conclusion}

ODS steels were studied in order to describe the resistance of their microstructure to the accumulation of vacancy type defects during implantation by $\mathrm{He}^{2+}$ ions/ irradiation by alpha particles. Positron Doppler broadening spectroscopy demonstrated a visible effect of new defect formation due to particle - atom collisions.

The lowest radiation damage was found in ODS Eurofer with the lowest chromium content (9 wt\%) which was manufactured by hot isostatic pressing. Other steels contain more chromium and were hot extruded. The most significant radiation damage was found for MA 956 with the highest chromium content. The radiation damage, showed as the change of the $S$ parameter, indicated slight dependence on the chromium content. This should be confirmed by further works.

\section{Acknowledgments}

Financial contributions from the EURATOM.CA and VEGA 1/0366/12 are acknowledged. Authors thank to Prof. Filip Tuomisto for management of DBS measurements at Aalto University in Finland.

\section{References}

[1] D.S. Gelles, J. Nucl. Mater. 233-237, 293 (1966).

[2] B. Kazimierzak, M. Prignon, Ch. Lecomte-Mertens, D. Coutsouradis, Anti-Corr. Meth. Mater. 37, 4 (1990).

[3] P. Horodek, J. Dryzek, M. Wrobel, Tribol Lett. 45, 341 (2012).

[4] G. Binning, U.S. Patent No. 4,724,318 (1988).

[5] G. Kinchin, R. Pease, Rep. Prog. Phys. 18, 1 (1955).

[6] J.F. Ziegler, M.D. Ziegler, J.P. Biersack, Nucl. Instrum. Methods Phys. Res. B 268, 1818 (2010).

[7] R.K. Willardson, E.R. Weber, M. Stavola, Identification of Defects in Semiconductors, Academic Press, Hardbound 1998, p. 376.

[8] J. Oila, V. Ranki, J. Kivioja, K. Saarinen, P. Hautojaervi, Appl. Surf. Sci. 194, 38 (2002).

[9] R. Krause-Rehberg, S.H. Leipner, Positron Annihilation in Semiconductors, Springer, Berlin 1998.

[10] V. Slugen, J. Veternikova, S. Kilpelainen, F. Tuomisto, Phys. Proc. 35, 28 (2012). 